\title{
PELATIHAN DESAIN PENGEMASAN DAN PEMASARAN KELOMPOK UMKM UNTUK MENINGKATKAN PENDAPATAN MASYARAKAT KELURAHAN DUPAK KECAMATAN KREMBANGAN KOTA SURABAYA JAWA TIMUR
}

\author{
Kusuma Wardhani Mas'udah ${ }^{*}$, Zainal Abidin Achmad ${ }^{2}$, Ita Sabilah Putri Chayani ${ }^{3}$, Nabila Alysia $^{2}$ \\ Multazam ${ }^{4}$, Ricky Fajar Adi Putra ${ }^{5}$ \\ 1,2,3,4,5 Universitas Pembangunan Nasional “Veteran” Jawa Timur, Jl. Rungkut Madya No.1, Gunung Anyar, \\ Surabaya, Jawa Timur, 60294, Indonesia \\ *Penulis korespondensi; email: kusuma.w.fisika@upnjatim.ac.id
}

\begin{abstract}
Abstrak: Pelatihan Desain Pengemasan dan Pemasaran Kelompok Usaha Mikro Kecil dan Menengah (UMKM) untuk Meningkatkan Pendapatan Masyarakat Kelurahan Dupak Kecamatan Krembangan Kota Surabaya Jawa Timur. Kelurahan Dupak merupakan desa yang memiliki cukup banyak UMKM, terutama digerakkan oleh pemuda dan ibu-ibu yang ingin meningkatkan kesejahteraannya. Kami mengidentifikasi permasalahan yang muncul di antaranya kurangnya pemanfaatan e-commerce akan berdampak pada lemahnya daya saing; pemasaran yang kurang efektif dan efisien; serta kurangnya pemanfaatan ponsel cerdas secara maksimal. Maka dari itu kami memberikan solusi berupa pelatihan pemanfaatan e-commerce untuk pengembangan UMKM di Kecamatan Dupak Kabupaten Krembangan. Sedangkan kegiatan pengabdian masyarakat ini dilaksanakan di Kelurahan Dupak Kecamatan Krembangan Kota Surabaya selama bulan Juli sampai Agustus 2021. Untuk mewujudkan program kerja dalam mewujudkan Tridharma Perguruan Tinggi yaitu memberikan pelatihan desain pengemasan dan pemasaran menggunakan platform Instagram, WhatsApp, dan Facebook dalam ponsel pintar sebagai sarana promosi, peningkatan motivasi, dan pendapatan bagi UMKM khususnya di kalangan pemuda dan ibu-ibu Kelurahan Dupak Kecamatan Krembangan Kota Surabaya Jawa Timur.
\end{abstract}

Kata kunci: E-commerce, re-branding, pemasaran, pengemasan, UMKM.

\begin{abstract}
Packaging Design and Marketing Training for Micro, Small and Medium Enterprises (MSMEs) to Increase Community Income in Dupak Village, Krembangan District, Surabaya City, East Java. Dupak Village is a village that has quite a lot of MSMEs, mainly driven by youth and mothers who want to improve their welfare. We identify problems that arise, including the lack of use of e-commerce which will have an impact on weak competitiveness; less effective and efficient marketing; and the lack of optimal use of smartphones. Therefore, we provide a solution in the form of training on the use of e-commerce for the development of MSMEs in Dupak District, Krembangan Regency. While this community service activity was carried out in Dupak Village, Krembangan District, Surabaya City from July to August 2021. To realize the work program in realizing the Tridharma of Higher Education, namely providing packaging design and marketing training using the Instagram, WhatsApp, and Facebook platforms on smartphones as a means of promotion, increased motivation, and income for MSMEs, especially among youth and women in Dupak Village, Krembangan District, Surabaya City, East Java.
\end{abstract}

Keywords: E-commerce, Rebranding, Marketing, Packaging, UMKM.

\section{PENDAHULUAN}

Perkembangan teknologi dan informasi yang sangat pesat saat ini, diciptakan untuk membantu manusia dalam meringankan aktivitas sehari-hari serta mampu memberikan informasi dengan cepat, tepat dan akurat. Salah satu gaya hidup baru adalah belanja melalui internet atau sering disebut juga e-commerce yang dalam Bahasa Indonesia diartikan sebagai belanja online. Proses jual beli yang dilakukan melalui internet dikenal dengan istilah e-commerce atau electronic commerce (Khasanah dkk., 2019).

E-commerce merupakan suatu proses menjual dan membeli produk-produk secara elektronik oleh konsumen dan dari perusahaan ke perusahaan dengan komputer sebagai media perantara transaksi bisnis (Laudon and Traver, 2017). E-commerce 
telah menciptakan pasar digital baru dengan harga yang ditawarkan lebih transparan, pasar global dengan perdagangan yang sangat efisien dan akses yang mudah (Laudon and Traver, 2017).

Pengguna media sosial yang semakin meningkat menjadikan fenomena tersendiri di era digital saat ini (Elvina, 2019). Begitu banyak toko online di Indonesia atau dikenal dengan e-commerce (Sunarti dkk., 2018). Tren pemasaran di dunia beralih dari yang semula konvensional (offline) menjadi digital (online).

Re-branding adalah istilah yang umum digunakan dalam dunia desain (Hastiningsih et al., 2021). Perubahan tampilan pada logo baru dibanding logo lama juga bervariasi, namun jika dibuat dua kategori yakni berubah sebagian, atau berubah seluruhnya dalam bentuk dan warnanya. Pola perdagangan dan pembelanjaan saat ini dari konsumen yang sudah mulai bergeser, dan adanya pandemik covid-19 yang menjadikan perdagangan e-commerce dan branding pengemasan menjadi pilihan yang baik untuk para pelaku UMKM. Sehingga UMKM bisa bertahan bahkan berpotensi berdaya saing untuk dapat menjangkau pangsa pasar baru (Fauzia and Persada, 2020). Usaha Mikro Kecil Menengah (UMKM) menjadi bagian penting dari sistem perekonomian nasional maupun daerah yang mampu mempercepat peningkatan ekonomi (Hafni and Rozali, 2017).

Kelurahan Dupak yang terletak di Kecamatan Krembangan Kota Surabaya bagian utara penduduk sebagian besar mata pencaharian dengan berjualan atau berdagang. UMKM di Kelurahan Dupak sudah dilindungi dari Lembaga Pemberdayaan Masyarakat Kelurahan (LPMK) dan beberapa ada yang di bawah naungan Kecamatan dan Disperindag atau Dinas Perindustrian dan Perdagangan. Jenis usaha jualan yang ditawarkan dari UMKM Kelurahan Dupak adalah produk makanan, minuman, hingga kerajinan tangan atau kriya.

Sistem pemasaran produk UMKM Kelurahan Dupak masih kurang maksimal yaitu sebagian besar masyarakat masih bergantung pada kegiatan bazar untuk mempromosikan produknya dan kegiatan berjualan masih secara konvensional di sekitar Kelurahan Dupak. Meskipun telah ada UMKM yang memasarkan produknya melalui media sosial, namun masih banyak pula UMKM yang belum mengetahui cara memanfaatkan $e$ commerce, branding, dan pengemasan untuk aktivitas sehari-hari serta kecanggihan teknologi tersebut. Kurangnya pemanfaatan e-commerce akan berdampak pada lemahnya daya saing dan pemasaran yang kurang efektif dan efisien (Ikmah and Widawati, 2018). Seiring dengan persaingan bisnis yang semakin tinggi dan minimnya pemanfaatan e-commerce dalam pengembangan bisnis
UMKM, maka diperlukan Pelatihan Desain Pengemasan dan Pemasaran Kelompok Usaha Mikro Kecil dan Menengah (UMKM) untuk Meningkatkan Pendapatan Masyarakat Kelurahan Dupak Kecamatan Krembangan Kota Surabaya Jawa Timur.

\section{METODE PELAKSANAAN}

Kegiatan pengabdian masyarakat ini dilaksanakan di Kantor Kelurahan Lantai 2, Kelurahan Dupak Kecamatan Krembangan Kota Surabaya antara bulan Juli sampai Agustus 2021. Pelaksanaan pengabdian dilaksanakan di tengah suasana pandemi COVID-19, dengan penerapan protokol kesehatan sangat ketat dan disiplin. Peserta pelatihan diukur suhu tubuhnya, dibagikan masker, dan diberikan hand sanitizer sebelum memasuki ruang acara.

Tahap persiapan meliputi perizinan oleh KKN Kelompok 38 UPN Veteran Jawa Timur sebelum masuk ke dalam lokasi mitra. Selain itu pendataan permasalahan kelompok UMKM Kelurahan Dupak dilakukan dengan mewawancarai pengurus PKK Kelurahan dan Ketua Kelompok UMKM secara langsung, untuk mengetahui permasalahan yang terjadi dan solusi untuk mengatasinya.

Tahap implementasi meliputi sosialisasi proyek dan pelatihan. Sosialisasi bertujuan untuk memberikan gambaran tentang rencana yang akan dilaksanakan. Kemudian membantu Kelompok UMKM untuk menjalankan rencana re-branding produk UMKM di Kelurahan Dupak yang berada di Kecamatan Krembangan.

Sedangkan tahapan pelaksanaan meliputi pelatihan mengenai desain pengemasan, pemasaran online dan re-branding kemasan UMKM Kelurahan Dupak. Kegiatan pengabdian kepada masyarakat ini juga membantu dalam pembuatan serta memaksimalkan penggunaan akun media sosial sebagai wadah promosi produk UMKM, re-branding, logo dan stiker pada kemasan. Kemudian tahapan evaluasi dan monitoring sebagai upaya pendampingan pelaksanaan kegiatan pengabdian kepada masyarakat bagi UMKM Kelurahan Dupak.

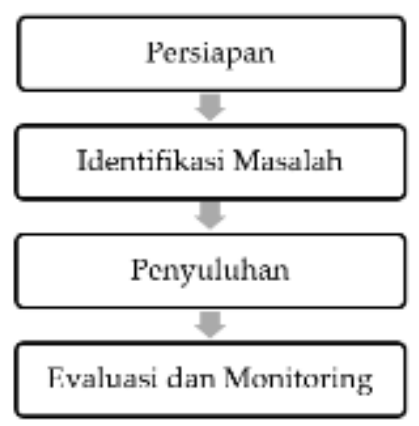

Gambar 1. Diagram alir kegiatan pengabdian masyarakat 


\section{HASIL DAN PEMBAHASAN}

\section{Penyuluhan Mengenai Pemasaran serta Pengemasan}

Kegiatan penyuluhan mengenai pengemasan dan pemasaran dilaksanakan pada hari Senin, 19 Juli 2021 pukul 09.30 - 13.00 bertempat di kantor Kelurahan Dupak, Kecamatan Krembangan. Pembukaan diawali oleh laporan ketua pelaksana pengabdian masyarakat. Pada laporan disampaikan bahwa maksud dari kegiatan pelatihan adalah untuk menentukan target pasar, kemudian mendapatkan customer, setelah itu menciptakan hubungan yang kuat antara UMKM dengan customer. Kegiatan pelatihan dengan materi pengemasan dan pemasaran ini mampu mengolah kebutuhan, keinginan, dan permintaan demi menarik pelanggan baru dengan menciptakan suatu produk yang sesuai dengan keinginan customer dan menetapkan harga yang menarik dengan memegang prinsip kepuasan pelanggan (Evasari, Utomo and Ambarwati, 2019).

Setelah itu dilanjutkan pelatihan mendesain ulang dan membuat logo, tampilan, serta pengemasan produk agar lebih menarik yang dilaksanakan pada hari Jumat, 23 Juli 2021 pukul 10.30 12.30 bertempat di kantor Kelurahan Dupak lantai 2, Kecamatan Krembangan. Selama ini, kebanyakan ibu-ibu UMKM menjajakan produknya hanya melalui usaha mulut ke mulut tanpa adanya toko atau wadah penjualan secara pasti untuk menjual produk-produk tersebut. Melalui pelatihan ini, kelompok UMKM dapat terbantu dalam pengemasan dan pemasaran produk-produk melalui media komunikasi yang telah berkembang. Peserta UMKM Kelurahan Dupak sebanyak 10 UMKM yang ditunjukkan pada Tabel 1.

Kelompok KKN Kelompok 38 UPN Veteran Jawa Timur membantu menyampaikan materi pemanfaatan e-commerce dan media sosial untuk pemasaran produk UMKM serta strategi branding yang efektif untuk keberlanjutan bisnis UMKM yang ada di Kelurahan Dupak, Kecamatan Krembangan, Kota Surabaya (Gambar.2). Peserta juga sangat termotivasi selama pelatihan berlangsung, antusias peserta diukur dengan banyak pertanyaan yang masuk saat pelatihan berlangsung. Selain itu bagi pemilik UMKM di Kelurahan Dupak, penggunaan media sosial sangat menarik dan membantu memperluas cakupan pemasaran produk UMKM.

Tabel 1. Data UMKM Kelurahan Dupak

\begin{tabular}{|l|l|l|}
\hline \multicolumn{1}{|c|}{ NAMA UMKM } & \multicolumn{1}{c|}{ NAMA PEMILIK } & \multicolumn{1}{c|}{ ALAMAT } \\
\hline Rejeki & Astuti & Jl. Dupak Rukun 6 No.21 \\
\hline Sidojaya & Sarmiyani & Jl. Sudirukun 2 No.1 \\
\hline Leny Collection & Leny,S.H & Jl. Dupak Bangunsari No.18 \\
\hline DMB (Dupak Makmur Bersama) & Nur Aini & Jl. Dupak Bangunsari IV No.15 \\
\hline Edelweis & Subechtiningsih & Jl. Bangunrejo No.41 A \\
\hline Datuk Berakzi & Beny Aria & Jl. Dupak Bandarejo 2 No.27 \\
\hline Tabarruk & Diah Oktavia & Jl. Dupak Bandarejo 1 No.66 \\
\hline Listik & Lis Sumarningsih & Jl. Dupak Bandarejo RSS Blok D No.229 \\
\hline Kayla & Rakmin & Jl. Dupak Bandarejo No.15 \\
\hline Dapur Yummy & Sriyatun & Jl. Rembang Selatan No.144A \\
\hline
\end{tabular}

Tabel 2. Susunan acara kegiatan pelatihan mengenai pengemasan dan pemasaran

\begin{tabular}{l|l}
\hline WAKTU & KEGIATAN \\
\hline $09.30-10.05$ & Persiapan acara \\
\hline $10.05-10.15$ & Pembukaan acara \\
\hline $10.15-10.20$ & Sambutan ketua kelompok kkn 38 \\
\hline $10.20-10.25$ & Sambutan dosen pembimbing kkn 38 \\
\hline $10.25-10.30$ & Sambutan ketua pkk Dupak, Krembangan \\
\hline $10.30-11.00$ & Pemaparan materi e-commerce \\
\hline $11.00-11.15$ & QnA \\
\hline $11.15-11.45$ & Pemaparan materi pemasaran, rebranding \& panjare \\
\hline $11.45-12.00$ & Sholat Dhuhur \\
\hline $12.00-12.15$ & QnA \\
\hline $12.15-12.45$ & Pemaparan materi foto produk \\
\hline $13.45-13.00$ & QnA \\
\hline
\end{tabular}

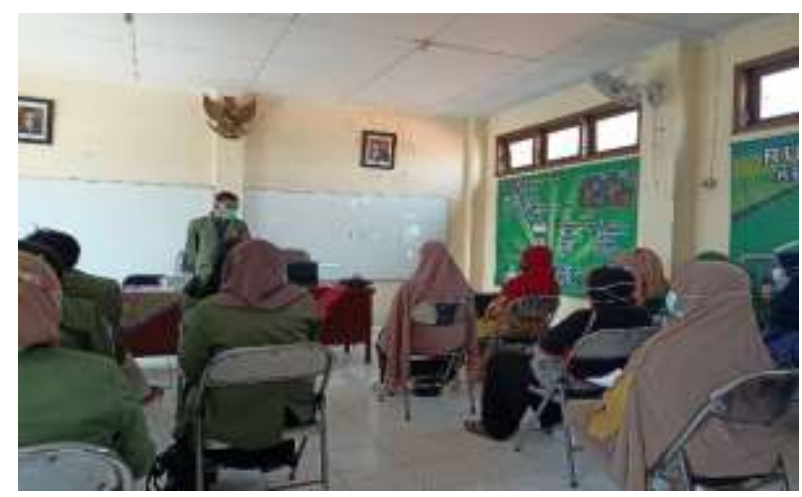

Gambar 2. Pelatihan pemasaran dan pengemasan oleh mahasiswa KKN

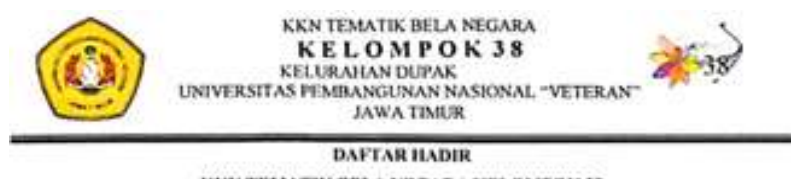

KKN TEMUTK BFIA NEGARI KELONFOK 38

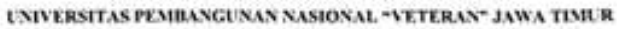

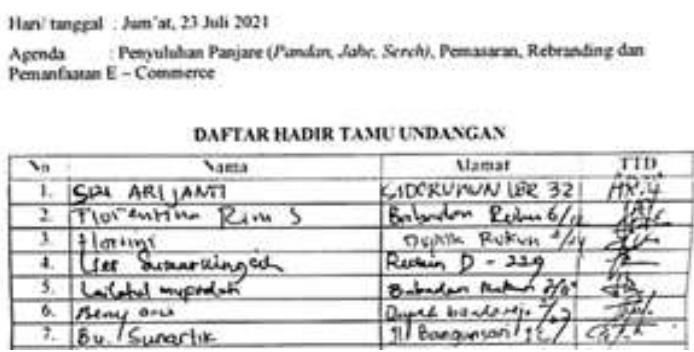

Gambar 3. Daftar hadir pesera kegiatan penyuluhan

\section{Pembuatan Serta Penggunaan Akun Media Sosial Dan Re-Branding}

Pemasaran secara online tentu memiliki dampak positif dan negatif bagi konsumen dan produsen. Dampak positif pemasaran secara online antara lain; pembeli bisa menikmati belanja secara lebih aman dan menyenangkan tanpa harus keluar rumah. Selain itu konsumen bisa memilih sendiri produk dari toko online sesuai keinginan berdasarkan informasi yang disediakan oleh toko online, sedangkan bagi penjual, toko online dapat menjangkau lebih banyak konsumen dari berbagai kalangan yang memungkinkan membeli produk yang ditawarkan. 


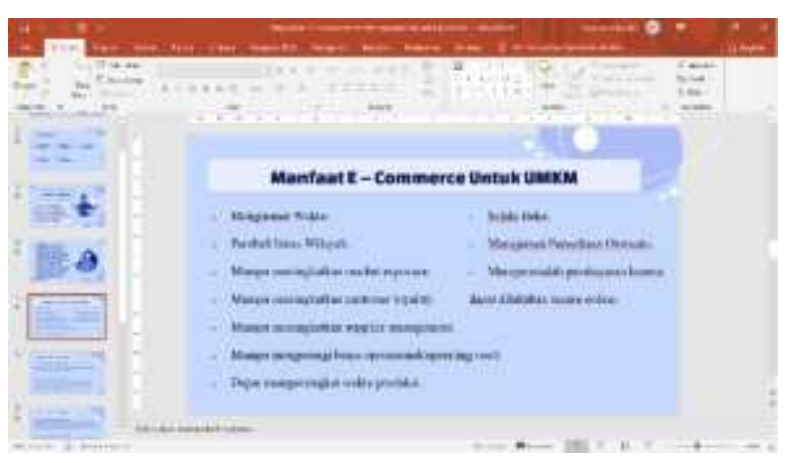

Gambar 4. Materi pemanfaatan e-commerce

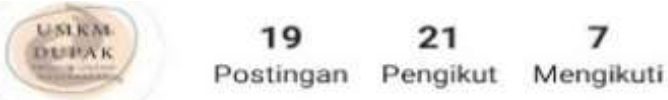

\section{UMKM Dupak}

Produk/Layanar

Informasi mengenai UMKM Dupak

Dupak, Krembangan, Surabaya, Indonesia 60179

Diikuti oleh nabilaalysia2, dyahoktasa, dan 1 lainnya

\begin{tabular}{|l|l|l|}
\hline Ikuti & Kirim Pe... & Email \\
\hline
\end{tabular}
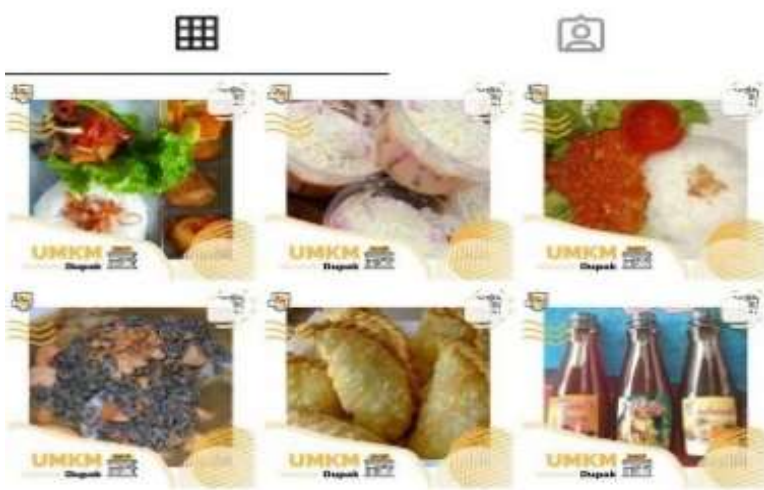

unyour 要

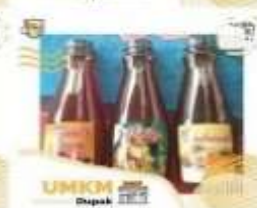

Gambar 5. Instagram UMKM Dupak

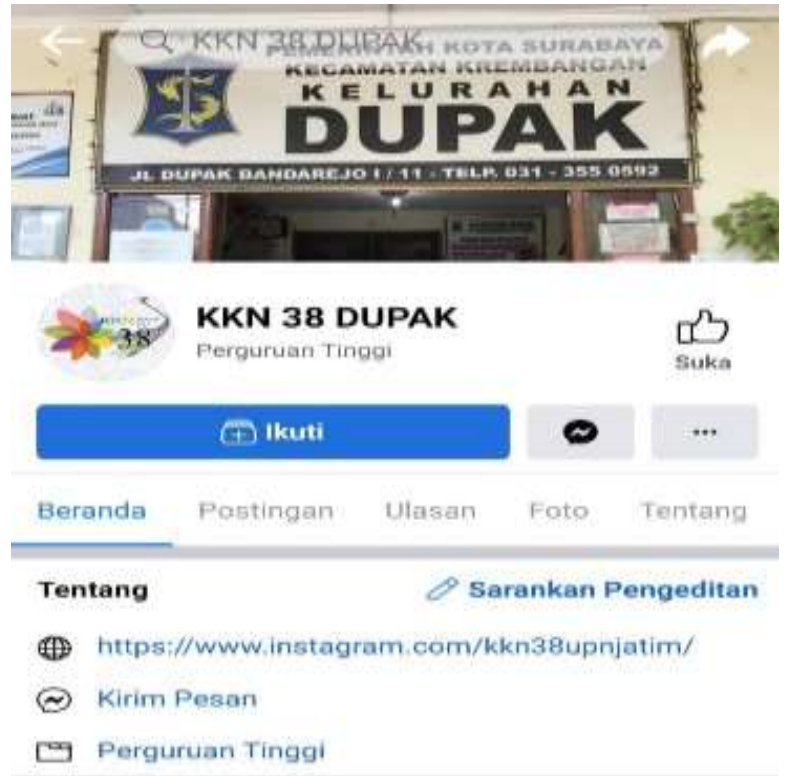

Lihat Semua

Gambar 6. Facebook UMKM Dupak
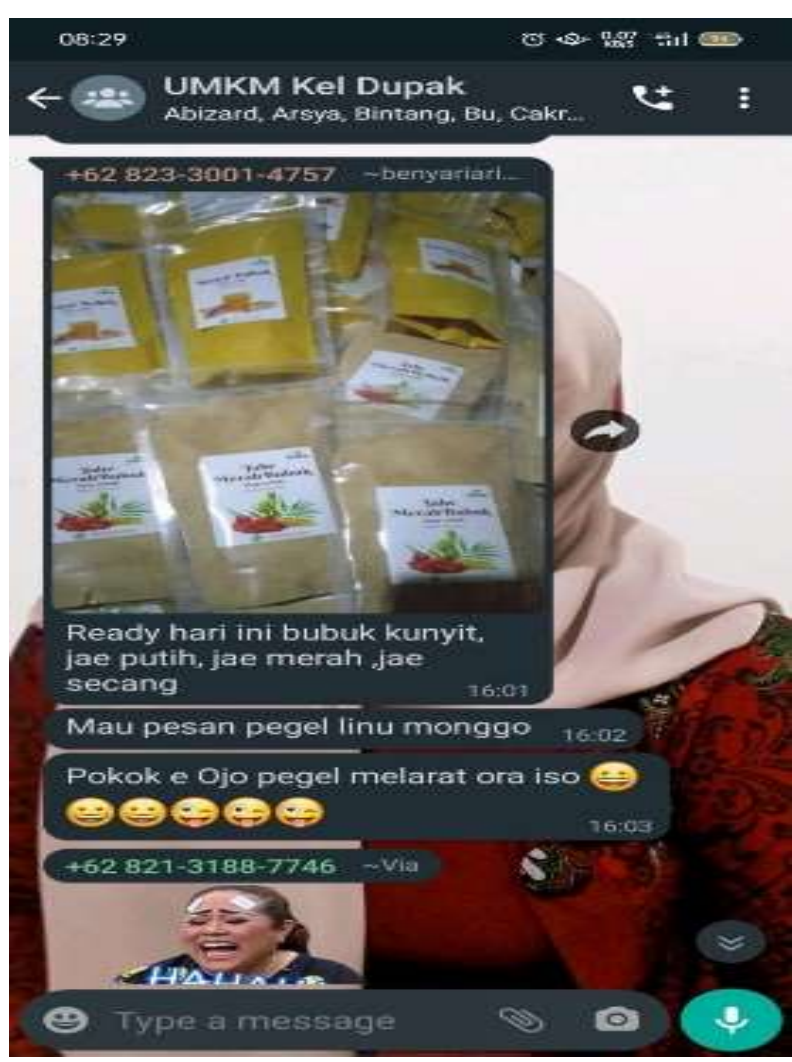

Gambar 7. Whatshapp UMKM Dupak

Sedangkan dampak negatif dari pemasaran secara online antara lain; pembeli kemungkinan akan terganggu dengan banyaknya layanan iklan online yang bersifat agresif atau bersifat memaksa. Sedangkan bagi penjual, berdagang online harus siap melayani pemesanan dari pembeli selama 24 jam dengan lebih sabar dan telaten.

Dampak positif dan negatif dari pemasaran secara online yang telah disebutkan, menarik perhatian Divisi Kewirausahaan KKN Kelompok 38 dalam pemasaran secara online dengan memanfaatkan media sosial Instagram dengan memberikan tampilan feed yang segar, mudah dipahami, dan menarik perhatian dari pembeli/konsumen. Pemasaran secara online menggunakan Instagram dan e-commerce ini dinilai dapat membantu UMKM Dupak dalam memasarkan dan mempromosikan produk.

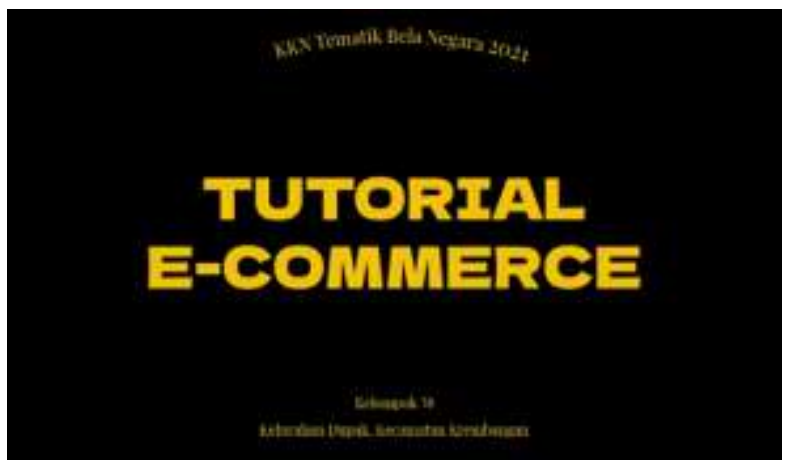

Gambar 8. Tutorial Pembuatan e-commerce

Sumber: https://www.youtube.com/ watch?v=AskAtTNe8 Y $\& p p=$ sAQA 
Langkah awal yang dilakukan dalam pemasaran online di platform Instagram adalah pembuatan akun. Pembuatan akun Instagram UMKM dupak diawali dengan membuat username yang mudah diingat dan dikenali oleh konsumen. Selanjutnya memberi logo atau foto profil yang menarik pada akun Instagram UMKM Dupak. Informasiinformasi penting juga ditambahkan pada Profil UMKM Dupak seperti biodata, dan alamat UMKM agar mudah diketahui oleh konsumen atau calon pembeli. Pembuatan akun Instagram yang telah dilakukan menjadikan akun Instagram UMKM Dupak lebih kekinian dalam tampilan, untuk mempromosikan produk ataupun layanan.

Berangkat dari pemahaman bahwa brand adalah asset yang perlu dijaga dan dipertahankan, maka perusahaan perlu melakukan langkah-langkah terkait dengan stabilitas dan citra. Selain itu sebuah brand juga merupakan perjalanan panjang yang di sana terekam semua jejak langkah dalam proses, tumbuh dan kembang bahkan pasang surut produk (Hastiningsih et al., 2021).

Selanjutnya, sesuai dengan kata re- yaitu ulang, re-branding logo berarti mendesain ulang atau mendesain logo baru. Rebranding berdasarkan dilandasi oleh beberapa alasan misalnya brand akan bergabung dengan brand lainnya, perluasan produk, ganti kepemilikan, perbaikan citra, perubahan nama, dan lain sebagainya (Hastiningsih et al., 2021).

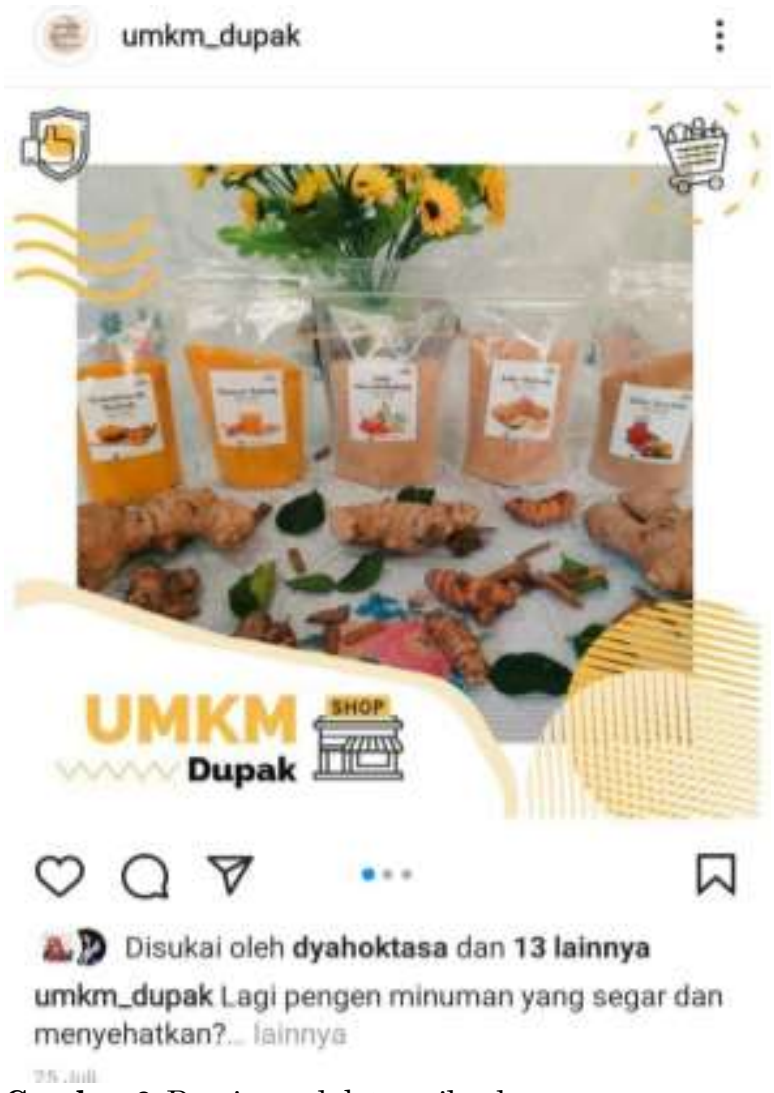

Gambar 9. Desain produk tampilan lama
Setelah dilakukan pelatihan desain pengemasan dan pemasaran bersama para pemilik UMKM dan ibu-ibu PKK yang terdapat pada Kelurahan Dupak, maka terjalin adanya komunikasi berkelanjutan didalam grup Whatshapp yaitu antara pemilik UMKM dengan KKN Kelompok 38 UPN Veteran Jawa Timur. Pada Gambar 9 dan Gambar 10 terlihat perubahan desain dari desain lama ke desain baru. Gambar 10 menunjukkan adanya tambahan tulisan manfaat dan khasiat dari produk yang ditawarkan. Hal ini dapat membuat para konsumen dapat mengetahui apa saja manfaat yang akan diperoleh ketika mengonsumsi minuman herbal tersebut dan semakin yakin untuk membeli produk tersebut.

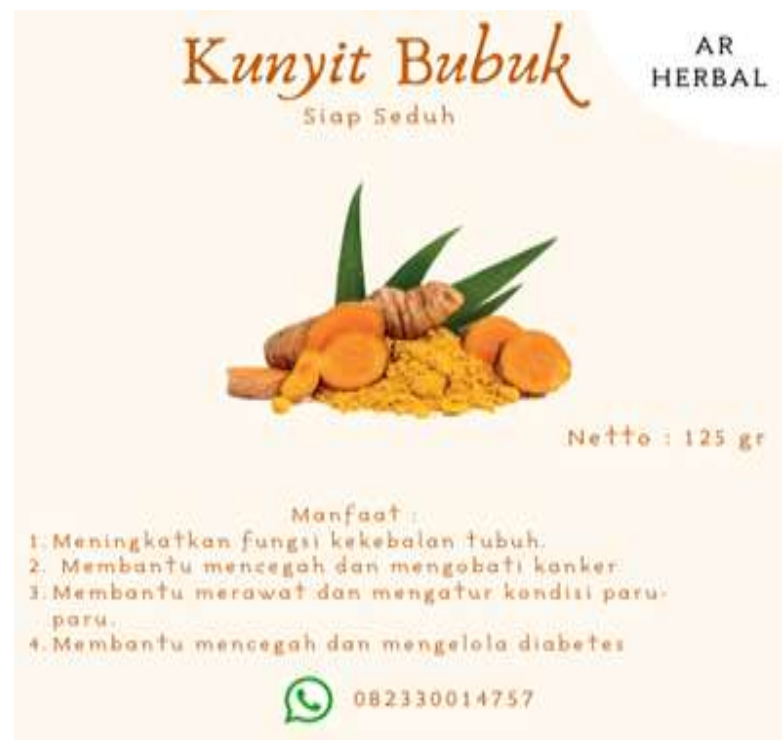

Gambar 10. Desain produk tampilan Baru

\section{Evaluasi dan Monitoring}

Awal penggunaan e-commerce dan penjualan melalui media sosial dianggap sudah baik dan menguntungkan bagi UMKM Kelurahan Dupak. Seiring berjalannya waktu selama pendampingan UMKM ini berjalan, diketahui bahwa penjualan melalui internet secara terus-menerus dirasakan sulit oleh ibu-ibu pelaku UMKM jika tidak dibantu oleh anak muda, hingga akhirnya ibu-ibu memilih untuk kembali menggunakan metode penjualan yang lama.

KKN Kelompok 38 UPN Veteran Jawa Timur menambahkan masukan, diantaranya: poster dan banner untuk pengembangan pemasaran. Selain itu, penggunaan logo dan sticker baru pada kemasan juga dilaksanakan pada masing-masing produk UMKM Kelurahan Dupak. Selain itu, UMKM Kelurahan Dupak tetap didorong untuk terus melakukan pemasaran dengan cara membagikan informasi produk UMKM melalui platform Instagram, grup-grup Whatsapp, dan Facebook. 


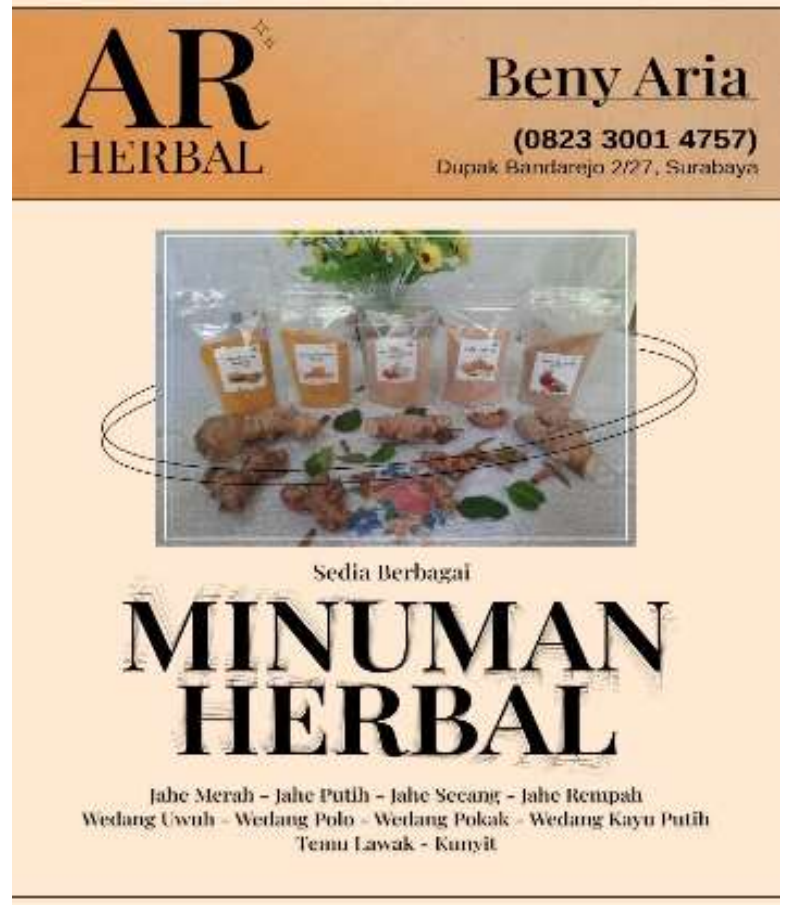

Gambar 11. Desain Poster

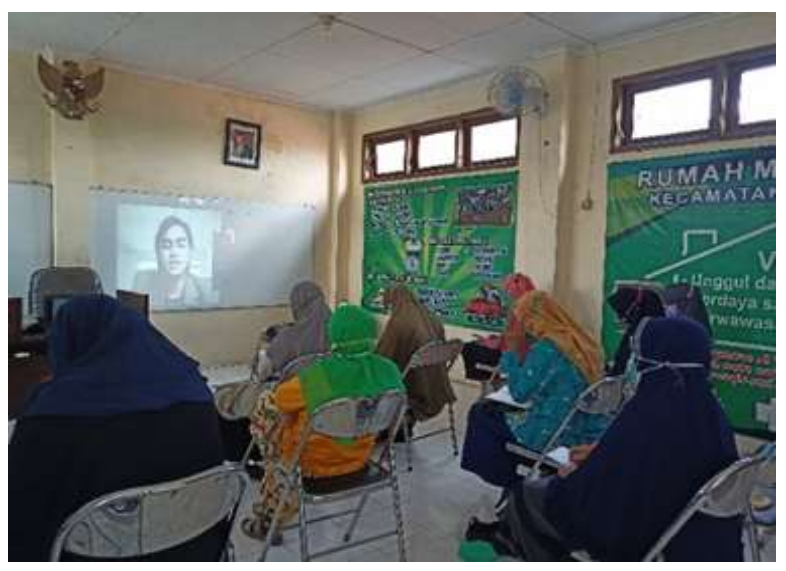

Gambar 12. Pelatihan mendesain ulang dan membuat $\log 0$

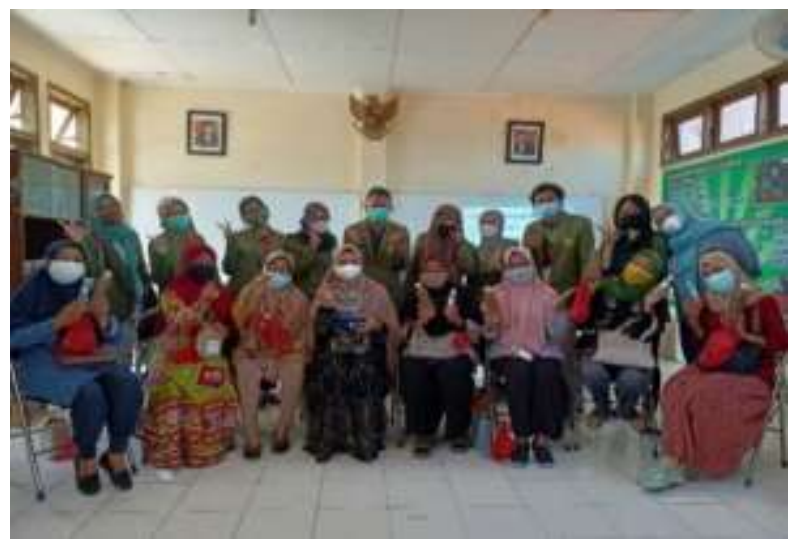

Gambar 12. Pelaku UMKM dan Tim Abdimas

\section{SIMPULAN}

Dari kegiatan pengabdian kepada masyarakat yang telah dilaksanakan dapat disimpulkan sebagai berikut: Pandemi COVID-19 sangat memberikan dampak yang sangat besar di segala sektor, terutama sektor ekonomi. Dampak dari pandemi ini mengakibatkan ekonomi masyarakat menurun, tidak terkecuali UMKM dan pendapatan setiap kepala keluarga. Pelatihan desain pengemasan dan pemasaran bagi Kelompok UMKM diadakan untuk meningkatkan pendapatan UMKM dan mengisi waktu luang serta dapat memenuhi kebutuhan pangan keluarga Kelurahan Dupak. Kegiatan yang dilakukan yaitu mempublikasikan produk UMKM Kelurahan Dupak dalam bentuk akun media sosial agar dikenal masyarakat luas.

Dengan adanya bantuan pelatihan dan aplikasi e-commerce mampu memotivasi para pelaku UMKM dan mitranya untuk melaksanakan pemasaran terhadap produk secara online. Minimnya pengetahuan mitra tentang manajemen pemasaran, MSDM, akun media sosial, e-commerce, desain kemasan, dan pengemasan yang menarik dan efisien, terbantu dengan adanya pelatihan dan pendampingan di bidang-bidang tersebut sehingga mitra menambah wawasan mereka.

Pelaku UMKM Kelurahan Dupak yang telah mengikuti serangkaian penyuluhan/pelatihan, diharapkan tetap dapat menjaga eksistensi produk, kualitas produk, kuntinuitas produk, perluasan pasar melalui promosi dan mampu membangun komunikasi dengan konsumen.

\section{UCAPAN TERIMAKASIH}

Pelaksanaan kegiatan Pengabdian Kepada Masyarakat ini telah melibatkan berbagai pihak, oleh karena itu pada kesempatan ini KKN Kelompok 38 Universitas Pembangunan Nasional "Veteran" Jawa Timur mengucapkan terima kasih dan penghargaan kepada:

1. LPPM Universitas Pembangunan Nasional "Veteran" Jawa Timur selaku koordinator pelaksanaan pengabdian kepada masyarakat berupa Kuliah Kerja Nyata Tematik Bela Negara Tahun 2021.

2. Dosen Pembimbing Lapangan yang selalu membimbing dan membantu kelancaran kegiatan Kuliah Kerja Nyata Tematik Bela Negara Tahun 2021.

3. Kelompok UMKM, PKK dan seluruh Pejabat Kelurahan Dupak Kecamatan Krembangan Kota Surabaya. 


\section{DAFTAR PUSTAKA}

Elvina, E. (2019) 'Pengaruh Penggunaan Media Sosial Terhadap Pengembangan Usaha Kecil Menengah (Ukm)', in Ecobisma (Jurnal Ekonomi, Bisnis Dan Manajemen), pp. 106118. doi: 10.36987/ecobi.v2i1.722.

Evasari, A. D., Utomo, Y. B. and Ambarwati, D. (2019) 'Pelatihan Dan Pemanfaatan ECommerce Sebagai Media Pemasaran Produk UMKM Di Desa Tales Kecamatan Ngadiluwih Kabupaten Kediri', Cendekia: Jurnal Pengabdian Masyarakat, 1(2), p. 75. doi: 10.32503/ cendekia.v1i2.603.

Fauzia, L. V and Persada, A. G. (2020) 'Rekonstruksi Media Sosial Instagram Sebagai Upaya Re-Branding Komunitas Kantong Pintar', Automata. Available at: https://journal. uii.ac.id/AUTOMATA/article/view/15519 ..

Hafni, R. and Rozali, A. (2017) 'Analisis Usaha Mikro, Kecil, dan Menengah (umkm) terhadap Penyerapan Tenaga Kerja di Indonesia', Ilmu Ekonomi dan Studin Pembangunan, 15(2), pp. 77-96. Available at: http://jurnal.umsu.ac.id/ index.php/ekawan/article/view/1034/pdf_58.
Hastiningsih, W. T. et al. (2021) 'Pendampingan Rebranding UMKM Gitar sebagai Bentuk Peningkatan Kinerja Pemasaran', Reswara Jurnal Pengabdian Kepada Masyarakat 2021, 2(1), pp. 131-139.

Ikmah and Widawati, A. S. (2018) 'Penerapan Ecommerce Untuk Pemasaran Pada Usaha Handycraft', Seminar Hasil Pengabdian Masyarakat, November (November), pp. 169-174.

Khasanah, F. N., Rofiah, S. and Setiyadi, D. (2019) 'Metode User Centered Design Dalam Merancang Tampilan Antarmuka Ecommerce Penjualan Pupuk Berbasis Website Menggunakan Aplikasi Balsamiq Mockups', JAST: Jurnal Aplikasi Sains dan Teknologi, 3(2), p. 14. doi: 10.33366/jast.v3i2.1443.

Laudon, K. C. and Traver, C. G. (2017) E-Comerse 2016 business, tecnology, sociey (12th ed.). England: Britis Library Cataloguint-in.

Sunarti, S., Puspita, R. H. and Ernawati, R. (2018) 'Pengembangan Pemasaran Usaha Kecil Kue Tradisional Rumahan Melalui Media ECommerce', Jurnal Abdimas Mahakam, 2(2), p. 85. doi: 10.24903/jam.v2i2.377. 